\title{
The National Innovative System Development Strategy as the Institutional Framework of Sustainable Development: Features and Risks of Russian Model
}

\author{
Andrei Aleinikov, Daria Maltseva, Olga Safonova, Anastasia Dedul, and Daria Kosareva
}

St. Petersburg State University, 13B Universitetskaya Emb., 199034 St. Petersburg, Russia

\begin{abstract}
This article is concerned with the features of the Russian national innovative system as the set of related various institutional structures in the context of the impact on the national sustainable development. The ability to quickly and efficiently master innovations, the speed of institutional changes and the openness of the economic system are analyzed as risks to the NIS development. It is shown that the low innovation susceptibility of society can become a serious obstacle on the way to the effective NIS. A range of issues related to the influence of political and sociocultural factors on the technological and investment abilities and capabilities of the country is problematized, the features of the functioning and development of the Russian national innovative system are shown.
\end{abstract}

\section{Introduction}

The COVID-19 pandemic has developed into the economic, social and humanitarian crisis affecting all key areas. According to most experts, Russia is faced with an unprecedented combination of three shocks: a sharp drop in oil prices, a decrease in demand for a wide range of Russian exports due to the global economic downturn, and a simultaneous shock to supply and demand as a consequence of the introduction of quarantine measures in the fight against the epidemic [1].

Under these circumstances, the innovation policy is the most important component of responding to the challenges of economic and social problems caused by an emergency situation, the main factor of economic growth, the lever of sustainable development [2-3].

Daron Acemoglu, notes that "but much we do not understand and are basing on guesses and imperfect knowledge», and adds that such key issues as "atrophying in the capacity of state institutions, because: erosion in public trust in state institutions (various reasons but related to inequality, perceived or real capture of politics by banks and business elites, and response to the global Önancial crisis); weakening of technocratic, autonomous civil service as a political strategy" [4].

Thus, the research issue underlying this article is primarily concerned with the features of the Russian national innovative system as a factor of "policy intervention in a changing world" $[5]$. 


\section{Materials and Methods}

The theoretical and practical issues of structural interdependencies, contradictions and opportunities, conflicts and risks of the NIS formation, factors of success and failure of innovation policy determined by "in the politics of policy" [6] are the subject of academic and expert debates.

By developing the theoretical provisions of J. Schumpeter about "creative destruction" as a result of a technological breakthrough, a number of works [7-10] formulate the main provisions of the concept of national innovation systems, the development of which in an article dedicated to the memory of Chris Freeman is referred to the most significant result of modern research of the theory and practice of innovation [11].

It can be agreed that the national innovative system is "a set of national state, private and public organizations and mechanisms of their interaction, within which activities are carried out to create, store, disseminate and use new knowledge and technologies" [12]. It is the set of various institutional structures that are interconnected both historically and technologically (including Research, Development and Engineering (RDE) or R\&D (Research and Development)) that influences the national innovative development and its direction. There is a departure from the "linear model of innovation", in which "knowledge" is modeled quite simply: the initiator of innovation is science, therefore, an increase in scientific contribution, for example, to the construction of a pipeline, will increase the number of innovations and technologies. In fact, ideas for innovation can come from many different sources and arise at any stage in the production of an "innovative product". Researches in the field of national innovative systems are focused, as a rule, on their development factors. We support the position that there is no general model of a successful national innovation system that is universal for all countries, since innovation processes are influenced by many different factors, including the unintended effects of government intervention. The interrelationships of these factors include general culture, values and institutions, training, innovation, competitiveness [13].

Our study uses the methodology of structural-object decomposition, highlighting the factors of innovative activity of the external environment, its institutional structure and framework conditions, the effectiveness and efficiency of institutional policy instruments, shortcomings in the functioning of links and missing elements as well as a system of policy instruments aimed at eliminating or smoothing failures of NISs for building the "profile" of the national innovative system and assess its efficiency [12].

Thus, two approaches to NISs are distinguished. The first, the so-called "narrow", implies that NISs are institutions that interact with each other for the purpose of innovative production. C. Edquist [14] calls them the "core" of the national innovation system: they produce, disseminate and adapt new technical knowledge. These institutions can be: industrial firms, universities or government agencies. The second is "broad", it is assumed that a number of other processes affect the innovation system: economic policy, features of the financial system, specificity and traditions of economic interaction, values, etc., that is, institutions that may be indirectly related to innovation growth. J. Niosi calls a set of such factors - "flows". In his opinion, it is "flows" that connect all institutions with each other [15].

It seems methodologically important for the purposes of our study that he proposed a classification of innovation systems by scale: local, regional, national and international. In his opinion, the national and regional (subnational) levels should be "privileged" for study and development. Whereas capital can "easily cross national or regional boundaries", then knowledge is not easily transported because of "its tacit nature, which is embodied in human intelligence". 


\section{Results and Discussion}

One of the key parts of the NIS are its social abilities, the set of socio-economic factors that contribute to the economic and technological development of the country or prevent overcoming technological backwardness. The factors that determine the "social capacity" of the state include national technical competence, experience in organizing and managing large-scale industries and projects [16]. The risks of NIS development include "innovative susceptibility" and "adaptability". Summarizing these approaches, "innovative susceptibility" can be defined as the ability of business entities to quickly and efficiently master innovations, create them, implement them in all industries in the present, and focus on the "future" in order to increase their competitiveness. At the same time, "a certain capacity for adaptation is present everywhere, but countries may differ from each other in this respect, and their capacity for adaptation may change over time".

The adaptability consists of two components:

- The speed of institutional change. The intellectual potential embodied in the country's population and the existing national institutional mechanisms limit the strength of its own technological potential. But technological change requires change, and the speed of institutional change directly depends on how changeable the institutions themselves are and how quickly the number of people using these institutions will grow. In this way, countries learn to change their institutional arrangements and then improve them as they gain experience. The restrictions imposed by the social potential on the successful introduction of more advanced technology are gradually weakening and make it possible to use it more fully;

- The economic system openness. It is defined, on the one hand, by competition as an opportunity for the creation and operation of new enterprises, for the sale and purchase of new goods and services. On the other hand, we are talking about obstacles to changes created by selfish interests, established practices, attitudes and customs of relations between enterprises, employers and employees. That is, in a closed and static economic system, the risk of social shocks is high. This is what led M. Olson to define defeat in war and political upheaval as a radical experience of clearing the ground, paving the way for new people, new organizations and new ways of working and trading better adapted to technological development.

Thus, the low innovation susceptibility of society can become a serious obstacle on the way to an effective NIS, since all the proposed state development programs, introduced techniques and technologies will require great efforts, while maintaining the risk of being rejected by society. However, the presence or successful development of social capabilities of the state through the development of the education system, the development and implementation of various innovative programs and projects at different territorial levels, retraining courses, etc. can help to level this risk and increase the level of adaptability.

An important component of the NIS as a factor of sustainable development is the national technological capabilities (possibilities), which are determined by innovations, investments and technologies. At the same time, "in the conditions of a knowledge-based economy, in determining and analyzing the effects of investment policy, it is critically important to shift the emphasis from economic components to political and sociocultural components" [17].

I.e., there is a close connection between the development of social opportunities of the state and investment policy, and as a result, technologies and innovations. The way in which this connection is organized determines the approach chosen by the state (technological or humanitarian) to the NIS creation. However, it is important for everyone that "for states striving for economic leadership, the processes of attracting investments, modernizing production and developing innovations should go parallel, not sequentially" [18]. Only in this case, according to researchers, the national technological capabilities can be effective as part of the NIS. However, in order to become possible, the network structure of interaction 
must be established; the network organization is the basic feature of the NIS. However, its absence or insufficient development affects the production of innovative product, since it is established in the context of distributed knowledge, which means that the preservation of the hierarchical organization characteristic of industrial society is a risk for the development of NIS. Consequently, there is "the need to move to communication network models of interaction between state and non-state actors based on the generation and combination of new knowledge, flexible solutions (as an alternative to bureaucratic universalism), broad involvement of various stakeholders in the policy-making process" [17]. Therefore, the development of "technological capabilities" is associated with the emergence of new forms of informal and formal interaction between representatives of various spheres of society. in the absence of channels for communication between entrepreneurs, the state and the scientific community, the risk of "non-birth" of innovative product increases, which affects the entire NIS. Community members are abstracted from each other, as a result: the national business community may not know about the existence of domestic technological products and turn to their imported counterparts; the research community, in this case, will not see interest in their work, which will lead to an increase in intellectual migration; the state will be forced to sponsor RDE development alone, since there will be no demand from entrepreneurs for domestic technologies.

However, even with the existence of such communication channels, the risk of "nonbirth" does not disappear. This is due, firstly, to a possible problem of language misunderstanding between communities, and secondly, to financing and reporting issues due to the specific nature of the innovative product.

The NIS core is its institutional component and the development path followed by a country is largely determined by institutional factors, often specific to a particular country, since its technological paths or "trajectories" of development are determined by the characteristics of national institutions and models of accumulated knowledge. They may not be suitable for an innovative environment.

Thus, national innovative systems form the following components: institutions that influence the national innovative and technological development; cultural and historical features; social opportunities that contribute to the innovative transformation of society; technological ability and RDE. The processes that form them affect the efficiency of the entire system. The more NIS components meet the efficiency criteria, the more efficiently and effectively the entire innovation system works.

Criteria for the NIS components' efficiency (institutional core, social and technological capabilities, RDE) are based on indicators (qualitative and quantitative), the analysis of which not only allows to assess the component efficiency, but to determine the national competitiveness in the global innovation space. The special analysis approach is required for the cultural and historical national context as a component of the NIS, since it consists of subjective elements. Consequently, its impact on the development of the national innovation system can be assessed only with a qualitative comparative analysis of countries.

According to the reports of the "Global Innovation Index" (GII), over the past 5 years, Russia has a stable position in the world innovation system, ranking 43-48 [19]. 


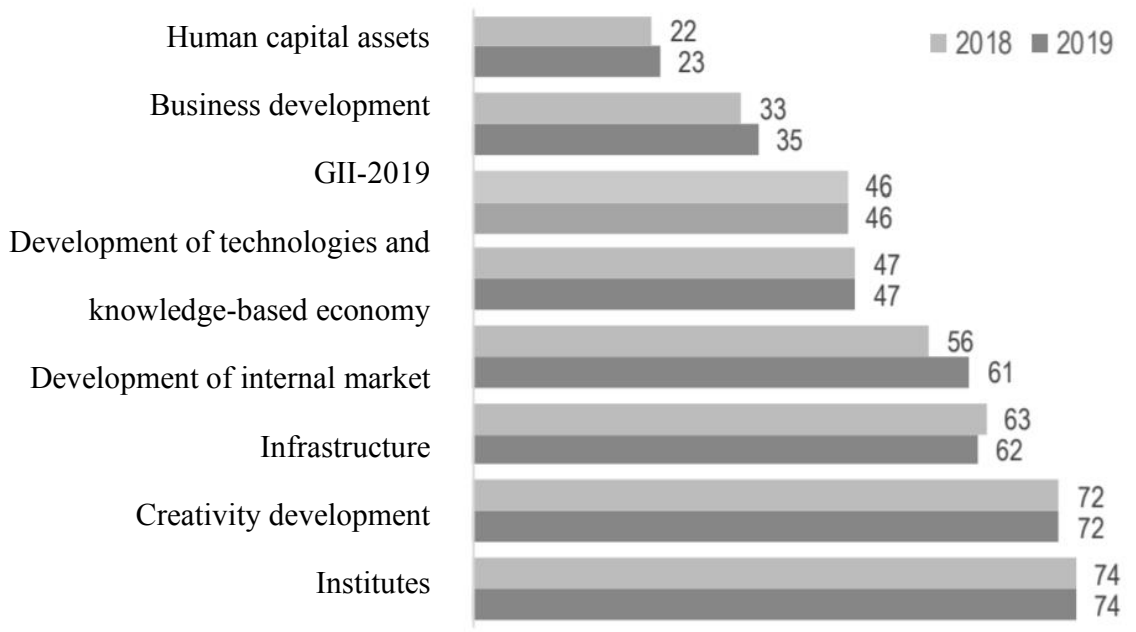

Fig. 1. Russia's rank in the Global Innovation Index by elements.

The innovation result can be influenced by two important factors of the NIS social capabilities: social sensitivity and the presence of interaction between the public and research institutions, the business community. The NIS failure to fulfill its fundamental functions of creating, storing, transferring and economically applying knowledge can be explained by the low motivation of actors to work within the NIS; outdated paradigm, underdevelopment of the innovative potential of actors, insufficient competence; lack of available resources and system elements capable of ensuring the functioning of its processes; violation and insufficient intensity of system connections; complexity and failure of the framework conditions [20].

As for innovation susceptibility, recent sociological studies [21] demonstrate a relatively high level of technology diffusion approval (about 50\% of respondents), but more importantly, "Russians declare a high level of readiness for personal use" of innovative products. However, the fear is caused by the average level of awareness of citizens about innovations: for example, only $29 \%$ of respondents can define "artificial intelligence" and $38 \%$ name the scope of its application. Consequently, if there is confidence in the technologies being introduced, the average level of technological literacy among the population remains, which has an impact on reducing individual demand for innovative products. That is, innovations become part of the ordinary life of citizens as a result of their implementation by the state, as a rule, at the level of public goods (public transport, public services, etc.), rather than individual satisfaction of demand, which results in one-sidedness of the innovation market and its products.

For Russia, the following feature is characteristic: with an increase in the cost of resources for innovation, the result of innovation continues to decline. A number of researchers define this feature as the Russian innovation paradox, which is expressed in the limited success in translating scientific inventions into innovative products. It is interesting that in many Russian regions the share of $\mathrm{RDE}$ expenditures in the gross regional product (GRP) is quite large, in terms of the scale of employment in science, Russia is one of the world leaders, but statistics show a relatively low innovative activity, that is, its efficiency is low. The national level of the innovation system development implies the inclusion of the entire country territory or its greater part in innovation activities. Therefore, that NIS cannot be considered successful if its innovative activity is concentrated only at one point. The development of the innovation infrastructure ensures the level of innovation activity in the region. The more efficient the infrastructure facilities, the more efficient the regional innovation system [22]. 


\section{Conclusion}

The analysis showed that under modern crisis conditions, the issues of adapting the national innovation system to changing realities become critical to compensate for the failures of the market and the state.

The issues considered do not exhaust the entire spectrum of problems and contradictions that arise in the course of the functioning of the national innovative system of Russia. The study of some patterns of innovative development allows us to single out a number of Russian features. First, the uneven development. Regional asymmetry persists, caused by resource inequality, remoteness from agglomerations, the presence or absence of large research centers or universities in the region. Secondly, the leading role of the state remains in the creation of infrastructure facilities. PPP principles are often not used productively and do not bring significant benefits. Thirdly, one of the problems in the development of infrastructure facilities is the discrepancy between the requested level of material and technical equipment and the real one. As a consequence, the low efficiency of innovations due to the low growth rate of new technologies, their rapid obsolescence as a result of a long period of implementation in production [23]. The development assistance system also has its own features. In Russia, a mixed model of support for innovative development prevails, with a narrowly focused profile. The state is trying to attract entrepreneurs to certain markets, to stimulate their development ("new markets", high-tech production, etc.), which corresponds to peculiarities of the "technological model" of NIS development, which assumes the domination of investments in technological innovations over social ones. As a result, progress in national innovation development is determined by a material indicator - a technological product of innovation.

In general, there is no "safety cushion" in the Russian system for promoting innovation, that is, the innovative product risks are not covered.

Summing up, it should be said that a unique national innovative system has formed in Russia, which can act as a factor of sustainable development.

The competitive advantages of Russian NIS are the development of scientific and technological competencies, unique practices of territorial development of the innovation infrastructure, and the presence of potentially attractive regions. The important tasks of state policy for the transition to a stage based on their own innovations and the formation of a postsimulation model of the NIS are overcoming innovative passivity, "forcing to innovate" and increasing the share of innovatively active regions with an emphasis on stimulating the results of the innovation cycle, reducing regulatory and administrative barriers, development of the market for highly qualified labor, management of conflicts between the new technological style and the barriers of the social and institutional system.

\section{Acknowledgements}

The study was carried out by a grant from the Russian Science Foundation (project No. 1918-00115) and with the financial support of the Russian Foundation for Basic Research (project No. 20-011-00393).

\section{References}

1. A. V. Polbin, S.G. Sinelnikov-Murylev, P.V. Trunin, Economic issues, 6, 5 (2020)

2. A. Ferrannini, E. Barbieri, M. Biggeri, M. Tommaso, World development., 24 (2020)

3. P. Anand, B. Ferrer, Q. Gao et al, Journal of human development and capabilities, 3 (2020) 
4. D. Acemoglu. Seminar at MIT - Massachusetts Institute of Technology, 9 (2020), https://economics.mit.edu/

5. H.J Chang, A. Andreoni, Development and change, 2, 324 (2020)

6. J. A. Robinson, Paper prepared for the World Bank ABCDE conference in Seoul, June (2009), https://scholar.harvard.edu/

7. C. Freemen, Technology and economic performance: Lessons from Japan (1987)

8. B-A. Lundvall, National innovation systems: Towards a theory of innovation and interactive learning (2010)

9. R. Nelson, National innovation systems. A comparative analysis (1993)

10. N.I. Ivanova, National innovation systems (2002)

11. B. Martin, M. Bell, Research policy, 7, 895 (2011)

12. O.G. Golichenko, Economic issues, 7, 35 (2014)

13. B.-Å. Lundvall, Industry and innovation, 1, 95 (2007)

14. C. Edquist, Systems of innovation: Technologies, institutions and ogranizations (1997)

15. J. Niosi, Research policy, 31, 291 (2002)

16. M. Abramovitz, The journal of economic history, 2, 385 (1986)

17. A.V. Kurochkin, I. A. Babyuk, Administrative consulting, 2, 8 (2018)

18. V.V. Reymer, A.V. Breusov, Agricultural journal in the Far East federal district, 2, 25(2012)

19. V. Roud, V. Vlasova, The journal of technology transfer, 3, 870 (2020)

20. O. G. Golichenko, Economic issues, 2, 97(2017)

21. Artificial intelligence: threat or opportunity? Russian public opinion research center, January (2020), https://wciom.ru/

22. S. Zemtsov, M. Kotsemir, Scientometrics, 120, 75(2019)

23. A.M. Nosonov, Russian journal of regional studies, 3, 436 (2019) 